\title{
Gvt crafts its own hospital quality standards, sans world-class local body
}

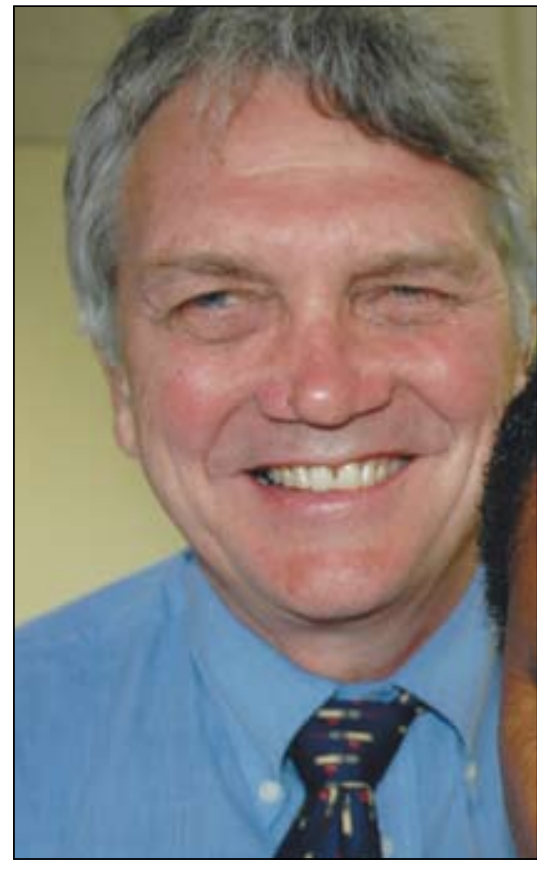

CEO of COHSASA, Professor Stuart Whittaker. Picture: Chris Bateman

Beleaguered public hospitals and clinics, due for a quality assurance 'make-over' and continual monitoring in advance of the much-vaunted National Health Insurance (NHI), may emerge little better in spite of strenuous government efforts.

The pivotal Office of Standards Compliance (OSC), tasked with drafting and monitoring minimum health care standards nation-wide, has parted ways with the local leaders in the field and could be headed for dysfunction, some experts believe.

After intermittent OSC consultation with, and several last-minute appeals for help from the local NGO with the strongest track record, the two bodies have reached a stand-off, neither talking to the other after disagreement on several issues. Several consultants to the OSC also believe that its failure to fully incorporate the best local advice and keep its top local advisor on board has led to poorly developed measurement standards, a dangerously accelerated process and deeply flawed pilot studies. The OSC denies this, claiming to have obtained 'enormous buy-in' from provincial teams and other stakeholders and to be on track with 'reliable, flexible and validated' measurement tools.
The 15-year-old, not-for-profit NGO the Council for Health Service Accreditation of Southern Africa (COHSASA) - has already independently assessed, monitored and accredited 55 public and 25 private sector local hospitals, based on essential performance indicators. It has more sets of standards accredited by the International Society for Quality in Health Care (ISQua) than any other health care accrediting body in the world and advises the World Health Organization (WHO) on patient safety and quality issues. Its quality assurance methods and protocols are the gold standard in Botswana, Swaziland and Lesotho and the City of Cape Town (clinics and community health centres), and are also in use to varying degrees at private and public hospitals in Namibia, Nigeria, Zambia, Tanzania and Rwanda.

A full quarter (28) of all hospices in South Africa are fully accredited by COHSASA with 97 headed towards full accreditation, hugely elevating their credibility and opening international funding doors, the Hospice and Palliative Care Association of South Africa told Izindaba.

In spite of this, the OSC is now using a British-based company, the Care Quality Commission, to audit the tools and processes it has developed, citing important similarities with the proposed local NHI funding model. South Africa's impending NHI system rests on hospitals and clinics in the private and public sector being gradually and incrementally accredited according to a set of minimum health care delivery standards. The systematic 'upgrade' of the larger public sector via preparatory quality assurance and monitoring has been touted by leading NHI architect, Dr Olive Shisana, and various health ministers as a vital rehabilitation tool and a pre-requisite for effective NHI functioning. Accreditation of any health care facility will allow it to access treatment funds from a several billion randsstrong central NHI coffer.

\section{Were they pushed or did they jump?}

The OSC/COHSASA collaboration ended this March after two years of ad hoc consultation in which the relationship grew increasingly strained over COHSASA CEO Professor Stuart Whittaker's insistence on specific standards of measurement and training. He and his staff spent an 'inordinate amount' of time commuting between Cape Town and Pretoria, staying in hotels and serving on pivotal OSC advisory committees, making themselves available to answer queries and giving advice, much of it last-minute. One source claimed COHSASA spent R250 000, but Whittaker declined to confirm this, saying only that an 'out of pocket' figure existed.

The systematic 'upgrade' of the larger public sector via preparatory quality assurance and monitoring has been touted by leading NHI architect, $\mathrm{Dr}$ Olive Shisana, and various health ministers as a vital rehabilitation tool and a pre-requisite for effective NHI functioning.

His counterpart, OSC director, Dr Carol Marshal, admitted that 'they put in resources' but strongly denied any imputation that COHSASA was 'ditched'

'They excluded themselves because they felt we should be using their product. There are products on the market for which one goes through normal tender procedures. The NGO model is not the only one out there. We ran a very open, participative process,' she asserted. Marshal added, 'It's a great pity. I think they made a decision that they would never be listened to. If you're going to be in on a process as an expert, you must be careful not to be a salesman.' She said she believes health minister, Dr Aaron Motsoaledi, 'feels that something as fundamental as quality assurance needs to be under the control of the government?.

Marshal added, 'It's a great pity. I think they made a decision that they would never be listened to. If you're going to be in on a process as an expert, you must be careful not to be a salesman.'

Each side complained to Izindaba that the other wanted to be 'both player and referee'. The OSC feels vulnerable at the prospect of paying for both standards development and 
ongoing monitoring, yet is arrogating that dual role to itself.

Down the line, the OSC is envisaged as independent of the health department, accountable directly to parliament. Debate looms over financing after officials confided that in the present economic climate, the best the OSC can hope for is seed funding. They claim their objectivity would be enhanced by rotating surveyors (whose quality COHSASA is severely sceptical about) through the provinces.

In February this year, after three months of little or no contact with COHSASA, the OSC suddenly asked it to pilot OSC standards at two hospitals, one community health centre and several clinics per province. Whittaker declined, reiterating reservations over time frames and a lack of proper measurement tools inherent in OSC standards.

\section{OSC 'reinventing the wheel' - experts}

A theme of 're-inventing the wheel' emerged during Izindaba's survey of experts in quality assurance-related fields, most of them involved with the OSC process. Speaking on condition of anonymity, one top provincial health official said: 'I would have thought that the national approach would be to try and avoid reinventing the wheel. COHSASA has already developed internationally accredited standards that are in place in many provinces and in other countries. It would have been easier as an approach to ask whether we cannot start with what we have and then develop it to suit the needs of the entire country and where we're trying to get to with the NHI. Instead we have this parallel process. At this stage it's not even clear what it will mean if you comply with the OSC's core standards. This just meets the bare minimum, never mind where we should be for the NHI. Another provincial official, a protagonist of the OSC model, claimed that COHSASA interventions seldom built ongoing capacity and that facilities often 'slipped back'.

A theme of 're-inventing the wheel' emerged during Izindaba's survey of experts in quality assurance-related fields, most of them involved with the OSC process.

A benefit and risk manager in private sector funding suggested using all quality assurance bodies with a local track record to implement OSC standards on the same basis that agencies do Black Economic
Empowerment (BEE) accreditation. Marshal acknowledged this but said it would depend on 'how costs play out - things are pretty tight right now. The risk manager added, 'Why reinvent the wheel when all the OSC need do is accredit programmes? These guys (like COHSASA) have the standards going and the track record.

\section{With national health minister} Dr Aaron Motsoaledi having set the health facility accreditation bar at 20\% of the country's 3716 hospitals and clinics by July next year, Marshal and her staff are under huge pressure to deliver.

Sharon Slabbert, Executive Officer for Health Service Delivery at the Hospitals Association of South Africa (HASA), said it was 'sad that people like COHSASA are being ignored by people who are trying to set standards for our country for something as important as the NHI. It's also crazy that the OSC has been given such a short time to implement such a complicated thing. Rather wait and do it properly. We'll be stuck with this.'

\section{Hospital accreditation target creates pressure}

With national health minister Dr Aaron Motsoaledi having set the health facility accreditation bar at $20 \%$ of the country's 3716 hospitals and clinics by July next year, Marshal and her staff are under huge pressure to deliver. She said the OSC standards had already been disseminated to hospitals and clinics which were doing self-assessments against them. 'We piloted the standards in all provinces in March and got their input. As a result there was a fair amount of technical work which we tried to do on a shoestring basis. But there was enormous buy-in from provincial teams to make standards reflect their reality and what they felt would be most useful.'

She denied that the resultant working group had failed to consider measurement tools and added: 'We feel we've validated and tested for reliability and made it quite flexible. She explained 'flexibility' as one province perhaps being more interested in infrastructure and another in mother and child health, adding: 'It's pretty robust'.

COHSASA successes graphically illustrate the potential for reducing the country's tragically high and avoidable infant mortality rates and addressing the overall parlous state of public health care delivery - when quality assurance is properly implemented. (South
Africa is one of only 12 countries in which mortality rates for children have increased since the 1990 baseline for the Millennium Development Goals (MDGs)).

A national sample study of COHSASAlinked hospitals by Professor Bob Pattinson, one of South Africa's top neonatal and maternity experts, shows that the higher their levels of standards compliance, the lower their infant mortality rates. Using COHSASA scores as the gold standard, he identified public hospitals that also used the Perinatal Problem Identification Programme (a perinatal care audit system). Pattinson found that at district hospitals, the better the standard of care (COHSASA score), the lower the perinatal mortality rate and the neonatal death rate. ${ }^{1}$ He told Izindaba that South Africa had 'pretty good' health coverage, 'but it's the quality of care where we fall down'.

This August, the Eastern Cape's Health MEC, Phumulo Masualle, conceded after an internal probe that 'a significant percentage' of the 100 premature baby deaths at Mthatha's Nelson Mandela Academic Hospital since January this year were due to 'clinical, administrative and infrastructural factors'. Pattinson's research indicates that patient referrals are a strong contributory factor to negative outcomes at tertiary hospitals. The Mthatha deaths follow multiple avoidable baby deaths at Mt Frere and Cecilia Makiwane district hospitals in that province three years ago amid outrage by the then deputy health minister, Nozizwe Madlala-Routledge, who was subsequently fired.

\section{Pattinson found that at district} hospitals, the better the standard of care (COHSASA score), the lower the perinatal mortality rate and the neonatal death rate.

\section{Praise song from the grave}

The late deputy health minister, Dr Molefi Sefularo, embraced the expertise of COHSASA in correspondence which Izindaba has seen, and was a champion of the quality assurance process. In a letter dated 11 February, less than two months before his death in a car accident this year, Sefularo describes COHSASA's role as a member of one of the OSC's technical quality improvement working groups as 'critical'.

'The areas identified for fast-track quality improvement, namely strengthening our commitment to our core values, ensuring facilities are clean, reducing waiting times, improving patient safety, strengthening the control of healthcare-acquired infections 


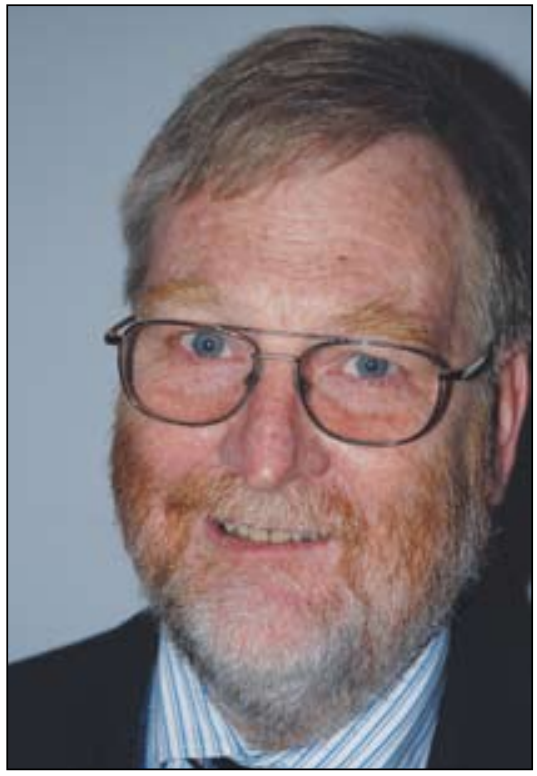

Professor Robert Pattinson, Director of the MRC's Maternal and Infant Health Care Strategies Research Unit.

Picture: Chris Bateman

and ensuring the availability of essential medicines and supplies lie at the centre of our commitment to better services. Our staff will be in touch with you in the near future with respect to the work to be done, he promised.

Observers of and participants in drawing up the much revised standards compliance framework say this was done without any 'attested instruments' to measure facility performance over time and without adequately prepared evaluators.

Says Professor Whittaker: 'We've expressed our ongoing willingness to assist but we're concerned about the processes used, in particular the lack of consultation with the Colleges of Medicine of South Africa and other academic bodies. We're also worried that the approach of the International Society for Quality in Health Care in developing accreditation standards has not been followed to any substantial degree'.

\section{He said that, in his view, the OSC process was neither appropriate nor adequate.}

Whittaker said that development and acceptance of standards by all role players was 'but the first step' in bringing about the accreditation of a health care facility. Before the accreditation of a facility, 'evaluative instruments' should be developed and surveyors trained to provide assessments. Once this was done, problems identified in facilities by the standards needed to be corrected before accreditation could be awarded. He said that, in his view, the OSC process was neither appropriate nor adequate.

COHSASA takes six months to a year to train facility assessors (OSC training is by comparison a crash course), followed by the painstaking enrolment of staff at hospital and clinics to 'secure their buy in'. Whittaker said it took a special kind of skill to persuade overworked nurses, doctors and administrative staff to shoulder the extra burden of, among other things, adverse event reporting and continuous monitoring. This, and the diligence required to scientifically validate quality improvement to enable full accreditation could take up to two years. He added that several public sector facilities that had failed to maintain COHSASA's required level of standards compliance had lost their accreditation status and would only regain it once they were back up to standard.

Marshal said core standards and quality assurance on their own would not cure the public health care sector's ills. 'They have to be part of a much bigger effort.' She said she was contemplating calling Whittaker to ask 'if he won't reconsider' (his role as a consultant). One observer quipped: 'I wouldn't hold my breath'

\section{Chris Bateman}

1. Pattinson R. Director MRC Maternal and Infant Health Care Strategies Research Unit, Dept O\&G, University of Pretoria. Unpublished abstract presented at the International Stillbirth Alliance meeting in Oslo, Norway in 2008 and an unpublished poster presented at the March 2010 Goudini Spa, Local Priorities in Perinatal Care conference. 